\title{
Tensile Stress-Strain Relationship For Ferro cement Structures
}

\author{
Azad A. Mohammed \\ and \\ Dunyazad K. Assi \\ E-mail : azadkadr@yahoo.com \\ E-mail dunya3s@yahoo.com \\ College of Engineering, University of Sulaimani
}

\begin{abstract}
Tests on fibrocement discs were carried out to measure tensile stress- strain relationship including testing wide ranges of matrix strength. Equations were proposed for calculating tensile strength based on the present test results and other results in the literature. A trilinear idealized model was proposed for calculating tensile stress - strain response of Ferro cement. The model was found to be accurate especially for higher strength Ferro cement. Later an analysis was carried out for calculating the loaddeflection relationship of Ferro cement beams based on moment - curvature relationship and bending theory of elastic beam. The analysis which based on the proposed tensile model was found to be accurate for Ferro cement beams and slab strips provided that the span / depth ratio less than 22.
\end{abstract}

KEYWARDS: Analysis, Beam, Elastic, Ferro cement, Flexure, Plastic, Slab, Strain, Tensile Stress

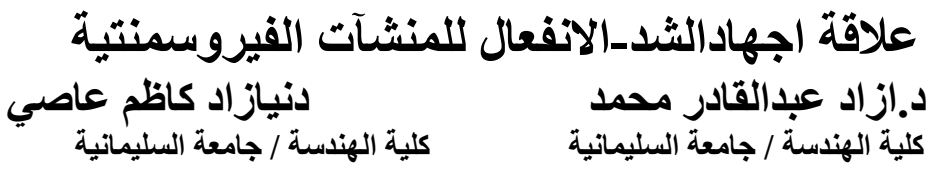

\section{الخلاصة}

في البحث الحالي تم اجراع فحوصات لقياس علاقة اجهاد الثد ـ الاففعال على نماذج فيروسمنتية لانواع مونة السمنت

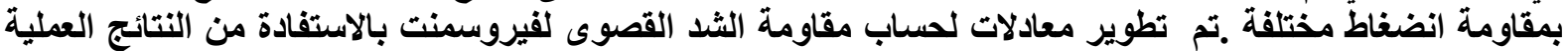

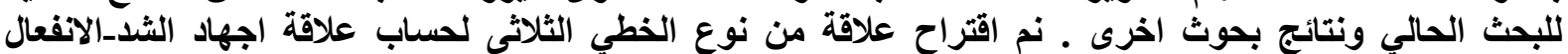

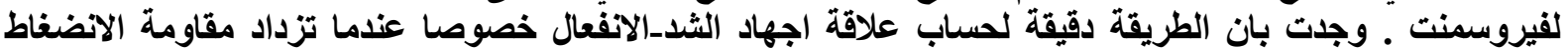

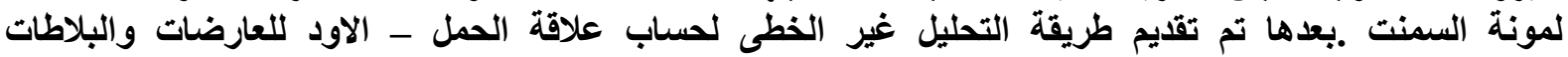

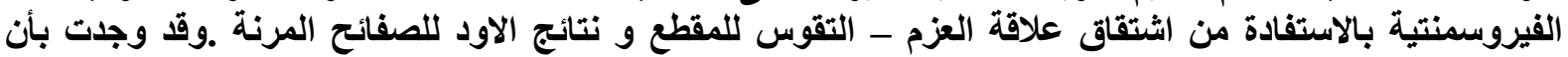

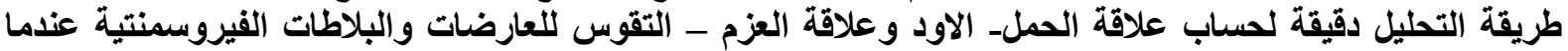
يكون نسبة الفضاء / عمق المقطع اقل من 22. 


\section{1- Introduction}

Ferro cement is considered as one of the nonconvential types of reinforced concrete usually known by its thin section and high tensile strength to weight ratio. Application of Ferro cement in which the section subjects to uniaxial tension can be seen in the case of silos, liquid retaining tanks, pipes, etc. Although the invention of Ferro cement turned back to the period of middle of the nineteenth century, researches for understanding mechanical and structural properties begin at the early 1970s. Nowadays the basic properties of Ferro cement were well understood and equations for design were proposed, that basically depend on the knowledge obtained from tests carried out during the last forty years.

ACI Committee $549^{[1]}$ prepared a state-of -the- art report to be a guidance for practical applications of Ferro cement. According to ACI 549 recommendations the role of Ferro cement mortar on tensile strength is neglected and the tensile strength is calculated from the load carried by the wire meshes divided by the sectional area. It should be noted that this recommendation is based on the results of tests carried out during the period from 1971 to 1977 [3, 5, 7] for Ferro cement sections made from a cement mortar of medium strength. Such recommendation is acceptable for calculating tensile strength of Ferro cement section made from normal strength mortar and greatly underestimates the tensile strength of high strength mortar Ferro cement. This is because the tensile strength of plain matrix alone is high and may be considerably greater than that calculated from the recommendations of ACI 549. For example, for a Ferro cement section of $25.4 \mathrm{~mm}$ thickness reinforced with five layers of wire mesh of $0.6 \mathrm{~mm}$ diameter, $12 \mathrm{~mm}$ spacing, and $412 \mathrm{MPa}$ yield stress, the tensile stress will be $1.91 \mathrm{MPa}$. If the compressive strength of matrix be $80 \mathrm{MPa}$ and cracking tensile stress is calculated from the relationship given by Shah and Balaguru ${ }^{[8]}$ the result which becomes $4.91 \mathrm{MPa}$. Therefore, one can found that the ultimate tensile stress calculated from ACI 549 recommendation is only $39 \%$ of the cracking stress. The later ratio is quite small and can be considered not reviewed. Therefore developing equations for predicting ultimate tensile stress of Ferro cement made of mortar of high strength is necessary. The aim of the present research is to provide an alternative equation for calculating tensile strength of Ferro cement applicable for wide range of matrix strength based on tensile stress tests and regression analysis. In the present study an attempt was made to develop a model for calculating tensile stress - strain relationship depending on the idealized trilinear response. Later, an analysis was introduced for calculating the complete load - deflection relationship of Ferro cement beams or slab strips based on derivation of moment- curvature relationship and results of elastic beam theory. The predictions of analysis were compared with the flexural test data carried out on ferrocement from literature to test the accuracy of the analysis.

\section{2- Experimental Work}

Ordinary Portland cement ( Type I ) was used for casting disc and compression specimens. Medium graded clean river sand passed by $100 \%$ on $2.36 \mathrm{~mm}$ sieve was used. For high strength mixes a high range water reducer (super plasticizer) of Gellunum type which is commercially available was used. Welded galvanized steel wire mesh fabric of $0.6 \mathrm{~mm}$ diameter and $12 \mathrm{~mm}$ spacing between wires and of $458 \mathrm{MPa}$ yield stress was used as reinforcement. Details of mixes and arrangement of reinforcement in each tensile test specimen can be found in Table 1. The tensile test specimens were discs of $152 \mathrm{~mm}$ and 25 $\mathrm{mm}$ thickness. Such type of specimens were cast inside the standard cylinders after putting wooden spacers to cancel a height of about $275 \mathrm{~mm}$ and to leave only $25 \mathrm{~mm}$ for thickness 
of the specimen. Figure ( 1 ) shows the mould used and the arrangement of Ferro cement wire mesh at casting period. All specimens were cured in the potable water at about $25^{\circ} \mathrm{C}$ for the period of 28 days and then left to dry in the laboratory for another 14 days before testing. For measuring the strain a foil of electrical strain gage was paste to the concrete surface in the direction of wire meshes but perpendicular to the direction of applied load. Figure 2 shows the specimen after testing which illustrates the position of strain gage. Disc specimens were tested in a manner similar to that of Brazilian split cylinder test by applying a load of a rate equal to $5 \mathrm{kN} / \mathrm{min}$. Using the following relationship given in the textbooks of concrete technology, the tensile stress can be calculated as follows

$$
f t u=\frac{2 P}{\pi L D}
$$

In which $f_{\text {tu }}$ is the splitting tensile stress, $P$ is the failure load, $L$ is the length of specimen, and $D$ is the diameter of specimen.

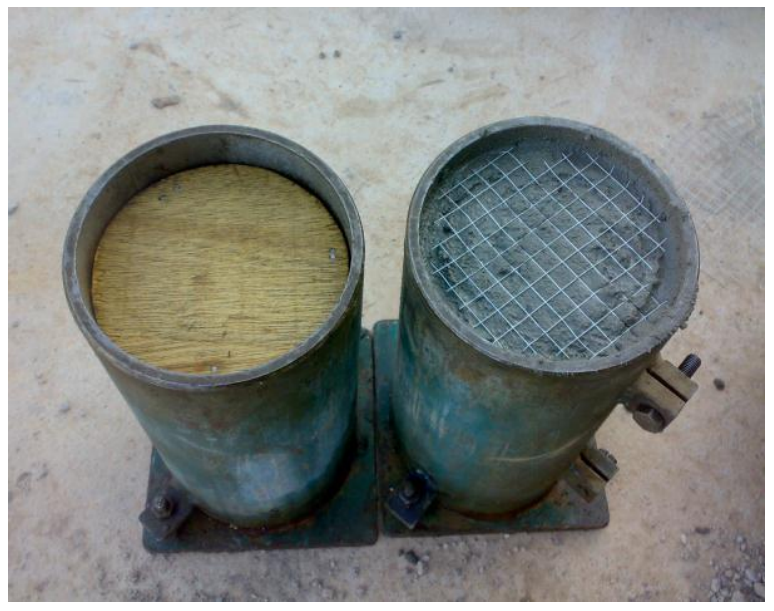

Figure ( 1 ): The mould used for casting disc specimens and wire mesh layer arrangement .

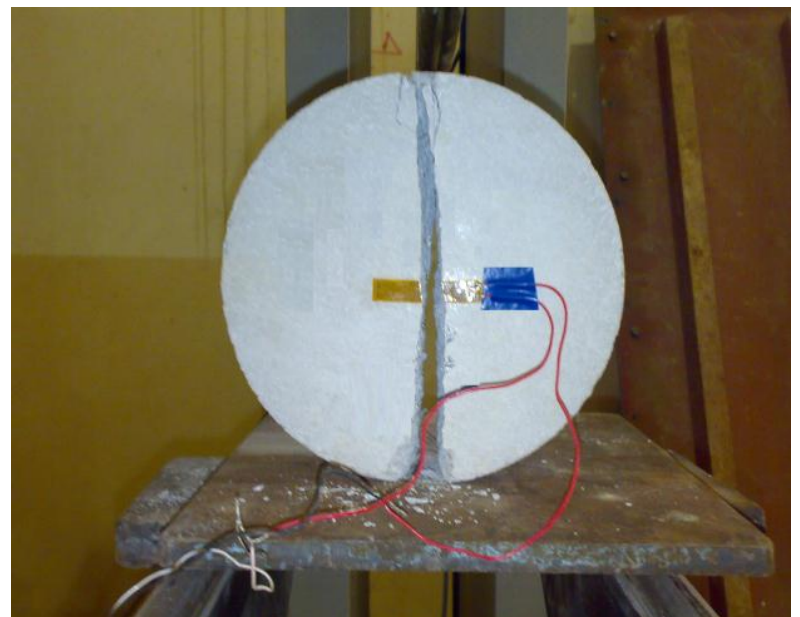

Figure ( 2 ): View of a disc specimen after testing.

\section{3-Test Results and Regression Analysis}

Test results of compressive strength and tensile strength are shown in Table ( 1 ). Tensile stress - strain relationship for the disc specimens are shown in Figures ( 3 ) to ( 13 ). It is shown that the slope of the curves ( or stiffness ) is high for the initial portion and the slope is reduced with increasing in stress. The curve in general become horizontal in the later stage which is considered to be a plastic stage. Three different stages are clearly observed in the most of the tensile stress - strain relationships. Such observation is not new and observed by others like Shah and Baluguru ${ }^{[8]}$ and Baluguru et al ${ }^{[2]}$. Figure ( 14 ) shows the variation of tensile strength with the wire mesh layers, indicating the positive role of reinforcement ratio on the tensile strength. Figure ( 15 ) illustrates the effect of mortar strength on the tensile strength. It is clearly shown that both of the reinforcement ratio and matrix strength affect the tensile strength of Ferro cement. Based on such results the tensile strength of Ferro cement can be represented by the superposition of the matrix strength and the stress carried by the wire mesh layers in the following relationship

$f_{t u}=f_{t m}+f_{t s}$ 
where $f_{t u}$ is the tensile strength of Ferro cement, $f_{t m}$ is the tensile strength of the matrix, and $f_{t s}$ is the tensile stress carried by the wire mesh. The tensile strength of matrix is the cracking stress and can be calculated from the expression given by Oluokun ${ }^{[6]}$, as follows:

$$
f_{t m}=0.2\left(f_{c}^{\prime}\right)^{0.7}
$$

Later the value of $f_{t s}$ is calculated from the result of subtracting $f_{t m}$ from $f_{t u}$ obtained from test results. In order to obtain the dependent variable $\left(f_{t s}\right)$ a regression analysis was carried out. The independent variable is the reinforcement index ( $\left.V_{R} f_{y R}\right)$. The two variables are combined in the following linear equation

$$
f_{t s}=\alpha+\beta\left(V_{R} f_{y R}\right)
$$

Statistical regression analysis based on least square method was carried out using the 14 data points and the values of constants $\alpha$ and $\beta$ was found to be 0.56 and 0.72 , respectively. Hence the final form of the tensile strength equation is as follows

$$
f_{t u}=0.2\left(f_{c}^{\prime}\right)^{0.7}+0.72 V_{R} f_{y R}+0.56
$$

The above equation has a correlation coefficient equal to 0.81 , mean value ( test / theoretical ) equal to 0.99 and standard deviation equal to 17\%. Figure ( 16 ) shows the relationship between the calculated and test tensile strength of Ferro cement. It is shown that there is a fairly good agreement between the two values.

Table ( 1 ) Detail of specimens and test results

\begin{tabular}{|c|c|c|c|c|c|c|c|}
\hline Mix & $\begin{array}{c}\text { w/c } \\
\text { Ratio }\end{array}$ & $\begin{array}{c}\text { No. of } \\
\text { Layers }\end{array}$ & $\begin{array}{c}\text { Ultimate } \\
\text { Load } \\
(\mathrm{kN})\end{array}$ & $\begin{array}{c}\text { Tensile } \\
\text { Strength } \\
(\mathrm{MPa})\end{array}$ & $\begin{array}{c}\text { Maximum } \\
\text { Vertical } \\
\text { Displacement } \\
(\mathrm{mm})\end{array}$ & $\begin{array}{c}\text { Cube } \\
\text { Compressive } \\
\text { Strength } \\
\left(\mathrm{N} / \mathrm{mm}^{2}\right)\end{array}$ & $\begin{array}{c}\text { Cylinder } \\
\text { Compressive } \\
\text { Strength } \\
(\mathrm{MPa})^{* *}\end{array}$ \\
\hline $1: 3$ & 0.64 & 3 & 21.6 & 3.23 & - & 24.86 & 19.89 \\
$1: 3$ & 0.64 & 3 & 19.2 & 2.87 & 1.90 & 24.88 & 19.90 \\
\hline $1: 3$ & 0.64 & 6 & 19.84 & 2.97 & 3.50 & - & - \\
$1: 3$ & 0.64 & 6 & 20.94 & 3.13 & 1.90 & - & - \\
\hline $1: 2.5$ & 0.60 & 3 & 22.14 & 3.31 & 3.25 & 22.83 & 18.26 \\
$1: 2.5$ & 0.60 & 3 & 15.47 & 2.31 & 1.00 & 32.25 & 25.80 \\
\hline $1: 2.5$ & 0.60 & 6 & 24.02 & 3.59 & 3.37 & 27.54 & 22.03 \\
\hline $1: 2$ & 0.53 & 3 & 24.59 & 3.68 & 3.20 & 26.85 & 21.48 \\
$1: 2$ & 0.53 & 3 & 16.78 & 2.51 & 2.60 & 30.99 & 24.79 \\
\hline $1: 2$ & 0.45 & 6 & 25.70 & 3.84 & 2.87 & 34.12 & 27.30 \\
$1: 2$ & 0.45 & 6 & 32.59 & 4.87 & - & 34.63 & 27.70 \\
\hline $1: 1$ & 0.43 & 3 & 26.20 & 3.92 & 1.84 & 51.36 & 41.09 \\
\hline $1: 1$ & $0.34 *$ & 3 & 32.11 & 4.80 & 1.51 & 64.80 & 51.84 \\
$1: 1$ & $0.34 *$ & 6 & 36.0 & 5.39 & 1.72 & 58.31 & 46.65 \\
\hline
\end{tabular}

* With $0.6 \%$ superplastcizer ( Gellunum type )

$* *$ Cylinder Compressive Strength $=0.8 \times$ Cube Compressive Strength 


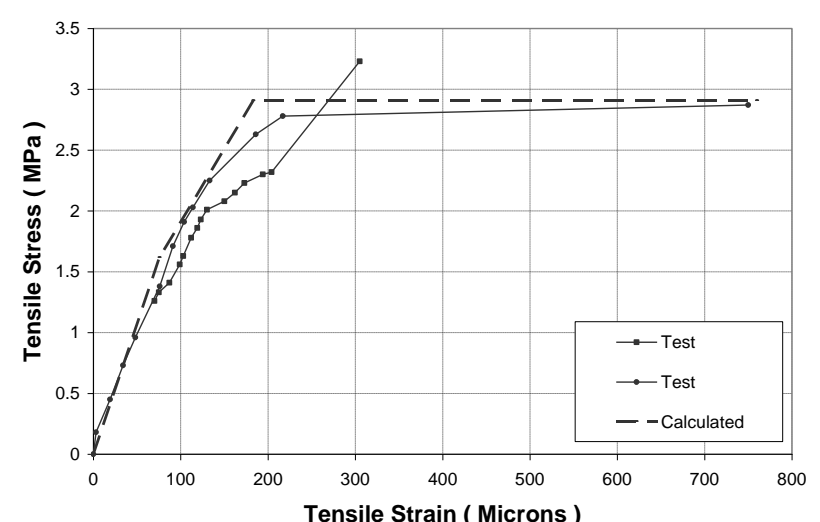

Figure ( 3 ) Tensile Stress - Strain Relationship of Ferrocement ( mix $1: 3$, three layers of wire mesh )

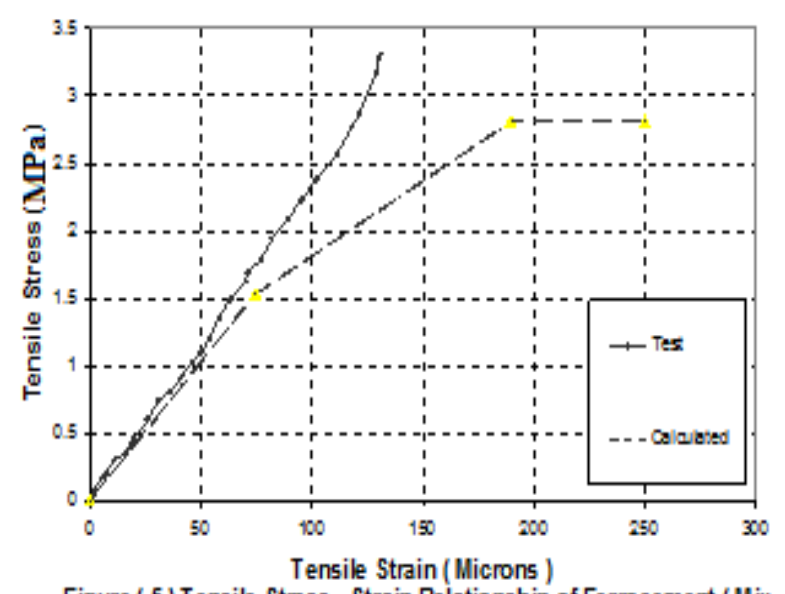

Figure ( 5 ) Tensile Stres5 - Strain Relationship of Ferrocement (Mix 1:2.5 . Three Layer of Wire Mesh )

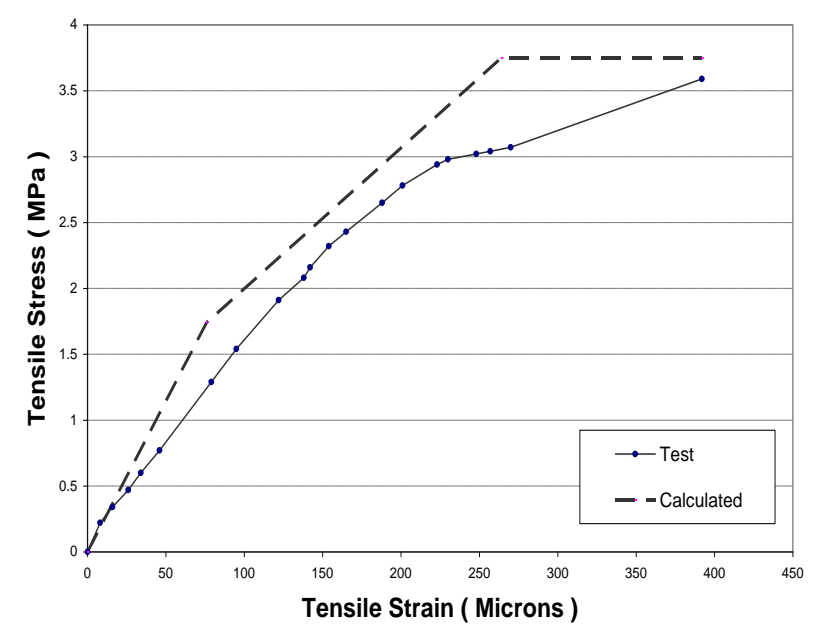

Figure ( 7 ) Tensile Stress - Strain Relationshipof Ferrocement ( Mix 1:2.5,Six Layers of Wire Mesh )

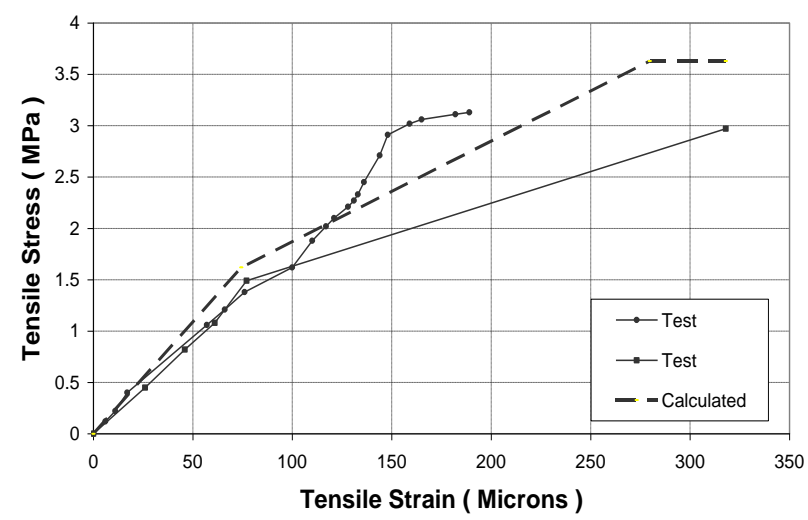

Figure ( 4 ) Tensile Stress - Strain Relationship of Ferrocement ( Mix 1:3, Six Layers of Wire Mesh)

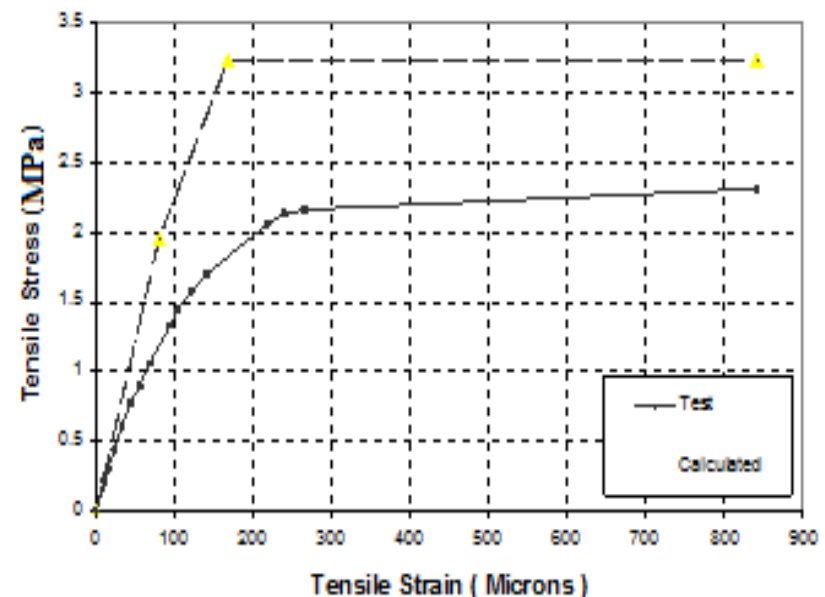

Figure (6) Tensile Stress - Strain Relationship of Ferrocement ( Mix 1:2.5, Three Layer of Wire Mesh )

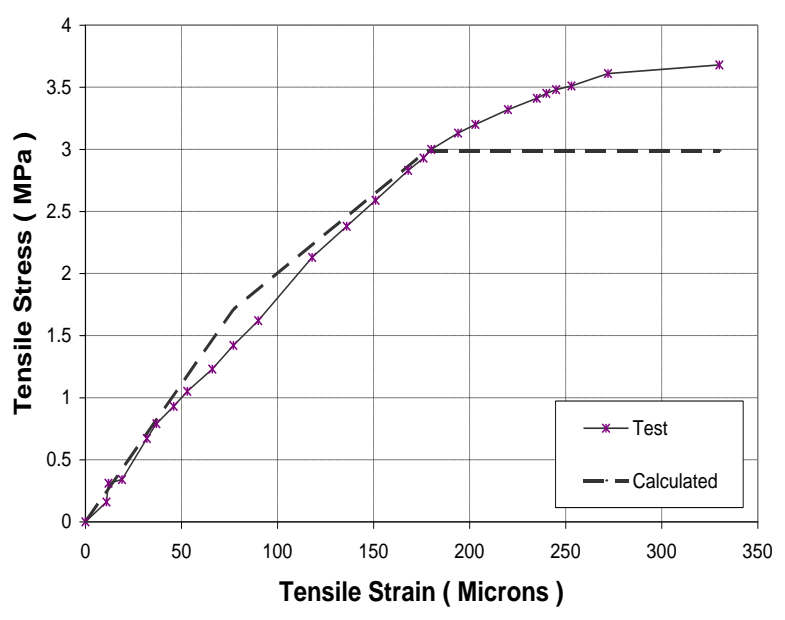

Figure ( 8 ) Tensile Stress - Strain Relationship of Ferrocement ( Mix 1:2, Three Layers of Wire Mesh ) 


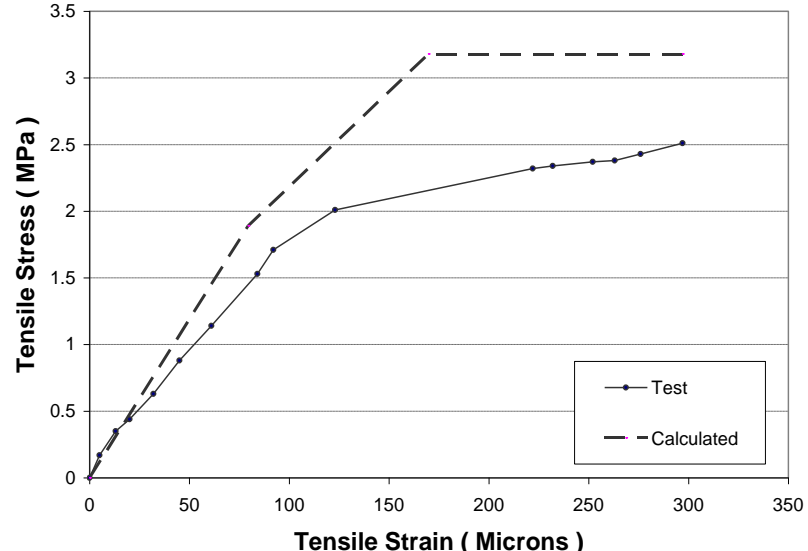

Figure ( 9 ) Tensile Stress - Strai Relationship of Ferrocement ( Mix 1:2,Three Layers of Wire Mesh )

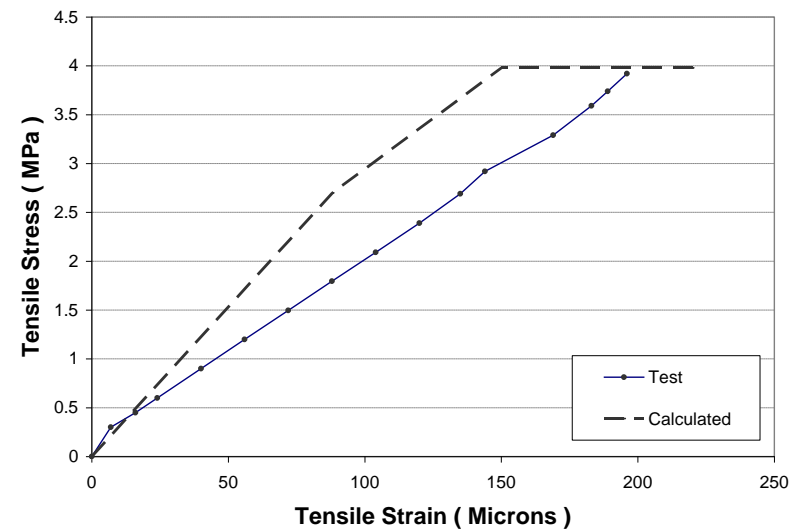

Figure ( 11 ) Tensile Stress - Strain Relationship of Ferrocement ( Mix 1: 1, Three Layers of Wire Mesh )

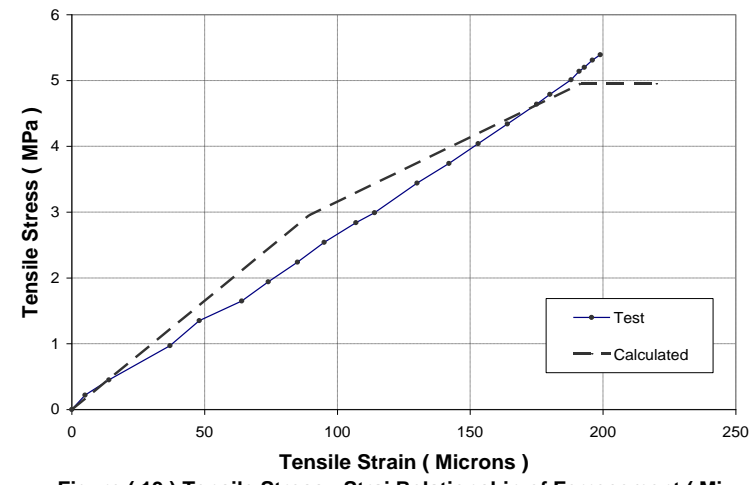

Figure ( 13 ) Tensile Stress - Strai Relationship of Ferrocement ( Mix 1:1H , Six Layers of Wire Mesh )

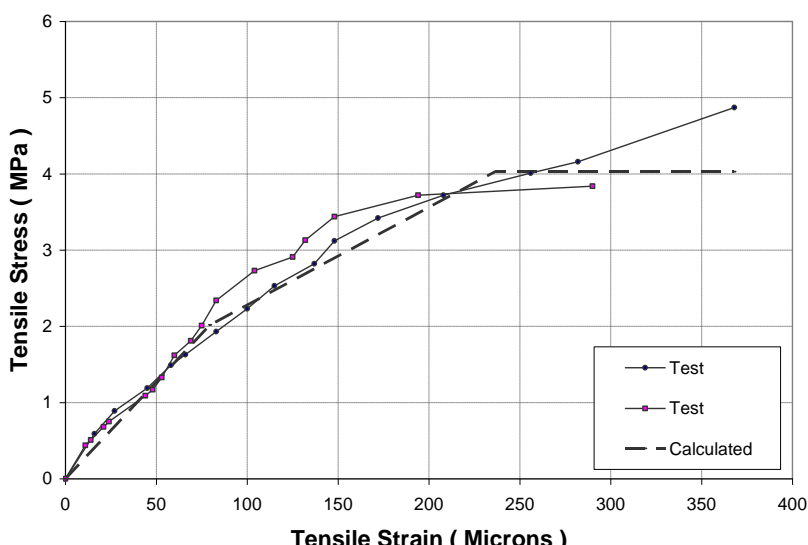

Figure ( 10 ) Tensile Stress - Strain Relationship of Ferrocement ( Mix 1:2 , Six Layers of Wire Mesh)

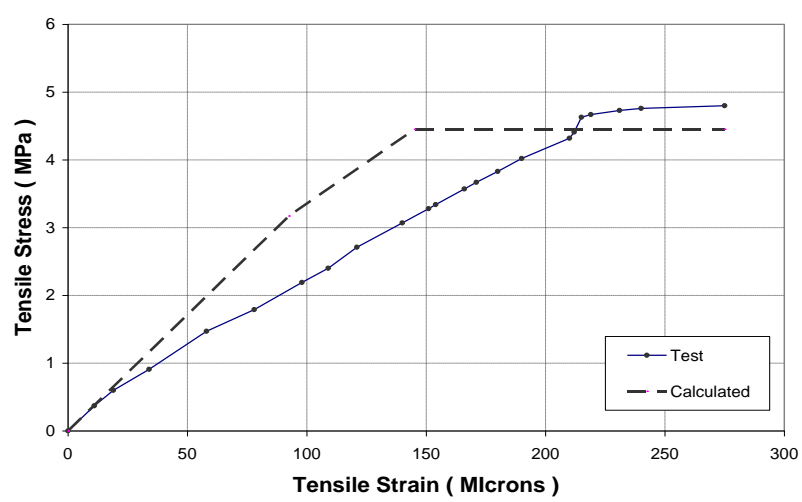

Figure ( 12 ) Tensile Stress - Strain Relationship of Ferrocement ( Mix $1: 1 \mathrm{H}$, Three Layers of Wire Mesh )

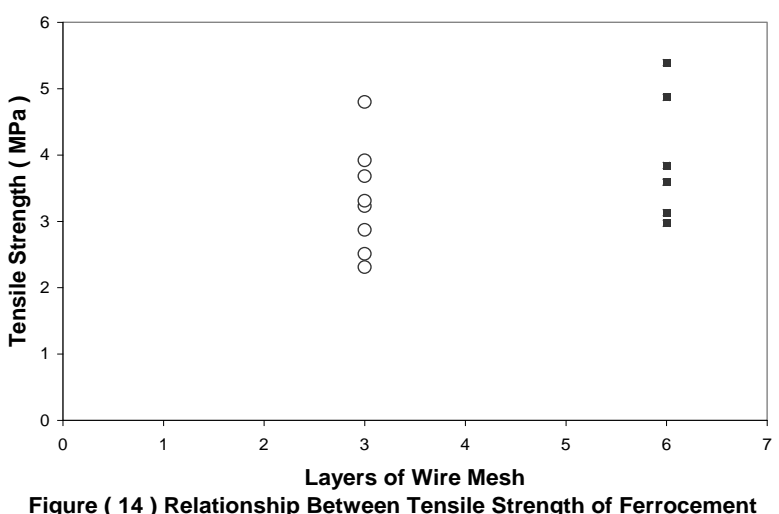

Figure ( 14 ) Relationship Between Tensile Strength of Ferrocement and Number of Layers of Wire Mesh

\section{4- Tensile Stress - Strain Model}

The proposed model for the tensile stress - strain relationship is based on experimental data obtained from present test results. The relationship is based on three portions : elastic, elasticplastic and plastic portion . Elastic stage terminates at cracking of the matrix and plastic stage begins at a value of stress equal to ultimate tensile stress and the other stage locates between 
the mentioned stages. Figure (17) shows the idealized form of the tensile stress - strain relationship.

The cracking strain is calculated for elastic Ferro cement material as follows:

$\varepsilon_{t m}=\frac{f_{t m}}{E_{c}}$

where $\mathrm{E}_{\mathrm{c}}$ is the elastic modulus of the composite given by ${ }^{[8]}$

$E_{c}=E_{m}\left(1+V_{R} n\right)$

$E_{m}$ is the elastic modulus of the matrix, can be calculated from the equation given be ACI Code as follows

$E_{m}=4730 \sqrt{f c^{\prime}}$

and $n$ is the ratio of elastic modulus of reinforcement to that of matrix $\left(\mathrm{E}_{\mathrm{R}} / \mathrm{E}_{\mathrm{m}}\right)$, and $\mathrm{V}_{\mathrm{R}}$ is the ratio of reinforcement in the section given by

$V_{R}=\frac{A_{s f}}{b h}$

where $A_{s f}$ is the area of the reinforcement in the section and $b h$ is the cross sectional area . The last variable needs to be assessed for constructing the tensile stress - strain relationship is the strain corresponding to the ultimate stress $\varepsilon_{\mathrm{tu}}$. For this purpose an approximation is made utilizing the trend of the cracking zone of the actual tensile stress - strain relationship. With increasing stress the stiffness is reduced due to cracking and here it is assumed that the ratio of the slope of the curve for the elastic -plastic range, $\psi$, to that of elastic stage, $\mathrm{E}_{\mathrm{c}}$, [ Figure ( 17 ) ] is equal to the ratio of tensile stress of matrix to the ultimate tensile stress, or

$\frac{\psi}{E c}=\frac{f_{t m}}{f_{t u}}$

From the shape of the portion the value of $\psi$ is calculated as follows:

$\psi=\frac{f_{t u}-f_{t m}}{\varepsilon t u-\varepsilon t m}$

Combining equations ( 9 ) and ( 10 ) leads to the following equation for calculating $\varepsilon_{\mathrm{tu}}$

$\varepsilon_{t u}=\varepsilon t m\left[1-\left(\frac{f_{t u}}{f_{t m}}\right)+\left(\frac{f_{t u}}{f_{t m}}\right)^{2}\right]$

Calculated stress- strain versus test tensile stress-strain relationships are shown in Figure ( 3 ) to (13) for all specimens. 


\section{5- Flexural Analysis of Ferro cement}

Having the Proposed idealized tensile model and an idealized compressive stress - strain given by Walraven and Spierenburg ${ }^{[10]}$ shown in Figure ( 18 ), Ferro cement structural member can be analyzed for moment - curvature and load - deflection relationships. Calculation of moment - curvature relationship is based on the equilibrium of forces and compatibility of strains. According to the compressive stress- strain and tensile stress- strain relationships different cracking stages exist and as a result nonlinear response is obtained. Hence, the material nonlinearity is included in the present analysis.

\section{5-1 Moment-Curvature Relationship}

\section{5-1-1 Elastic Stage}

Stress and strain distributions for this stage are shown in Figure ( 19-a ). Depth of the compression zone $\mathrm{c}$ is calculated from equilibrium of compressive and tensile forces acting on the section, or

$\mathrm{C}-\mathrm{T}=0$

It is assumed that the elastic modulus calculated from Eq. ( 6 ) is valid for compression and tension zone of the section and as a result the depth of compression zone for the elastic stage is equal to that in tension zone and equal to $\mathrm{h} / 2$. For this stage the moment - curvature relationship is given by

$$
M_{e}=\frac{b E c \phi}{3}\left(h^{3}-3 h^{2} c+3 h c^{2}\right)
$$

Where $b$ is the width of the section, $\phi$ is the curvature, $h$ is the depth of the section and c is the depth of compression zone. Substituting $c=h / 2$ the moment- curvature relationship becomes

$$
M_{e}=\frac{b E c h^{3} \phi}{12}
$$

This stage is valid until the matrix cracks in which the corresponding curvature becomes

$$
\phi_{e}=\frac{\varepsilon t m}{(h-c)}
$$

Substituting $\mathrm{c}=\mathrm{h} / 2$, the above curvature limit becomes

$$
\phi_{e}=\frac{2 \varepsilon t m}{h}
$$

\section{5-1-2 Elastic-Plastic Stage (1)}

Stress and strain distributions for this stage are shown in Figure ( 19-b ). For this stage the depth of compression zone is given by 


$$
c=\frac{\sqrt{(\psi \phi h)^{2}+(E c-\psi)\left[\varepsilon_{t m}^{2}(E c-\psi)+\psi \phi^{2} h^{2}\right]}-\psi \phi h}{\phi(E c-\psi)}
$$

$\psi$ is the slope of elastic - plastic portion of the tensile - stress strain relationship given by Eq. ( 10 ). Moment-curvature relationship for this stage is as follows

$$
M_{e p 1}=\frac{\phi}{3}\left[E_{c}-\psi\right] c^{3}+\psi \phi h c^{2}-\psi \phi h^{2} c+\frac{E c \varepsilon m^{3}}{3 \phi^{2}}+\frac{\psi \phi}{3}\left[h^{3}-\frac{\varepsilon_{t m}^{3}}{\phi^{3}}\right]
$$

This stage is valid until the curvature becomes

$$
\phi_{e p 1}=\frac{\varepsilon t u}{(h-c)}
$$

\section{5-1-3 Elastic-Plastic Stage ( 2 ):}

Stress and strain distributions for this stage are shown in Figure ( 19-c ). Equilibrium of forces lead to the following value of $\mathrm{c}$ for this stage is given by

$$
c=\frac{-f_{t u}+\sqrt{f_{t u}{ }^{2}+E_{c}{ }^{2} \varepsilon_{t m}{ }^{2}+E c \psi\left(\varepsilon_{t u}{ }^{2}-\varepsilon_{t m}{ }^{2}\right)+2 f_{t u} E_{c}\left(\phi h-\varepsilon_{t u}\right)}}{\phi(E c-\psi)}
$$

Moment - curvature for this stage is given by

$$
M_{e p 2}=\frac{E_{c} \phi}{3} c^{3}+\frac{f_{t u}}{2} c^{2}-f_{t u} h c+\frac{E c \varepsilon_{t m}^{3}}{3 \phi^{2}}+\frac{\psi}{3 \phi^{2}}\left[\varepsilon_{t u}{ }^{3}-\varepsilon t{ }^{3}\right]+\frac{f t u}{2}\left(h^{2}-\frac{\varepsilon_{t u}{ }^{2}}{\phi^{2}}\right)
$$

The terminating point of curvature for this stage is given by

$$
\phi_{e p 2}=\frac{f_{c u}}{E_{c c}}
$$

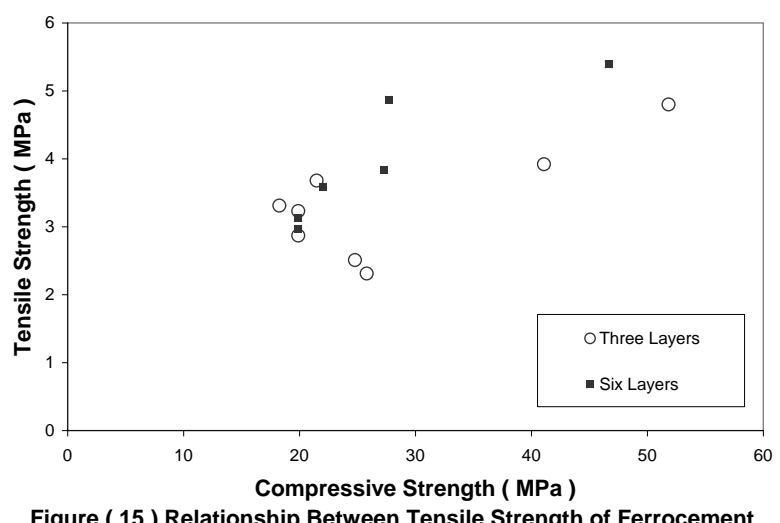

Figure ( 15 ) Relationship Between Tensile Strength of Ferrocement and Compressive Strength of Concrete

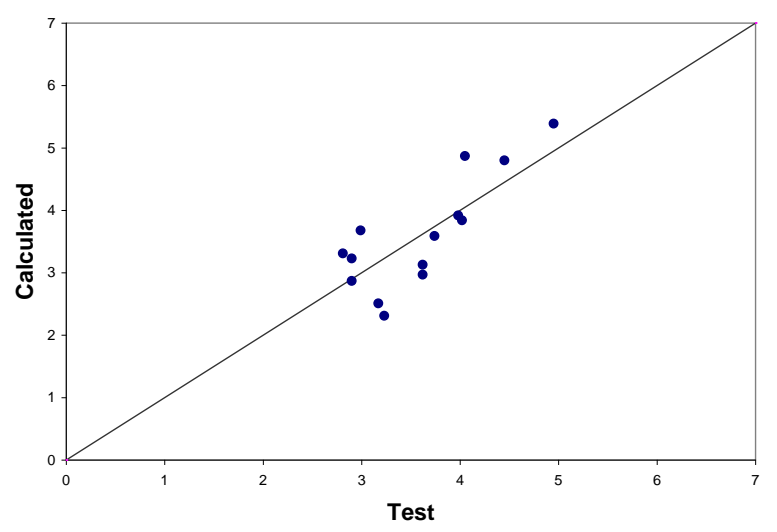

Figure( 16 ) Calculated Versus Test Tensile Strength of Ferrocement 


\section{5-1-4 Elastic-Plastic Stage (3):}

Stress and strain distributions for this stage are shown in Figure (19-d ). For this stage the value of depth of compression zone $c$ is calculated as follows

$$
c=\frac{f_{t u}\left[h-\frac{\varepsilon t u}{\phi}\right]+\frac{\psi}{2 \phi}\left[\varepsilon_{t u}{ }^{2}-\varepsilon_{t m}{ }^{2}\right]+\frac{E c \varepsilon_{t m}{ }^{2}}{2 \phi}+\frac{f_{c u}{ }^{2}}{2 \phi E c}}{f_{c u}+f_{t u}}
$$

The relationship between moment and curvature is given by

$M_{e p 3}=\frac{b}{2}\left[f_{c u}+f_{t u}\right] c^{2}-b f_{t u} h c+\frac{b \varepsilon_{t m}{ }^{3}}{3 \phi^{2}}\left[E_{c}+\frac{f_{c u}{ }^{2}}{E_{c}{ }^{2}}\right]-\frac{b f_{c u}{ }^{3}}{2 \phi E_{c}{ }^{2}}+\frac{b \psi}{3 \phi^{2}}\left[\varepsilon_{t u}{ }^{3}-\varepsilon t m^{3}\right]+\frac{b f_{t u}}{2}\left[h^{2}-\frac{\varepsilon t u}{\phi^{2}}\right]---(22$

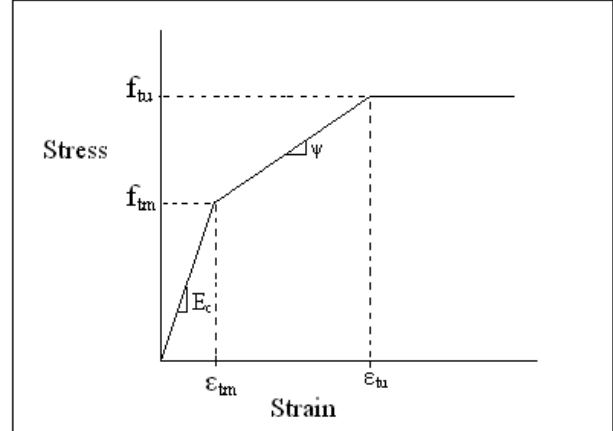

Figure (17) Idealized Tensile Stress - Strain Relationship

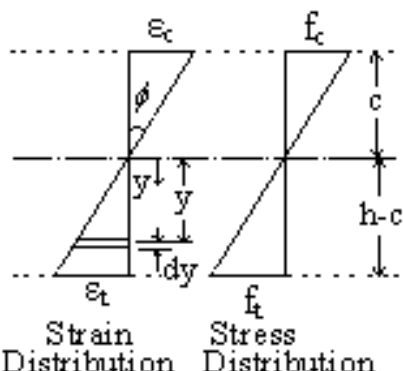

(a) Elastic Stage

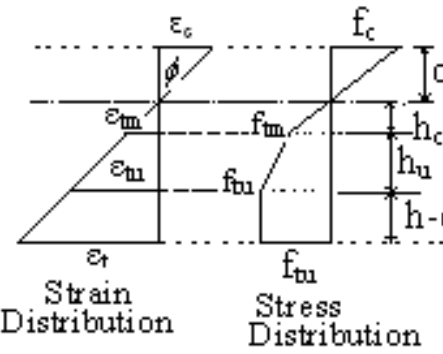

(c) Elastic-Plastic Stage ( 2)

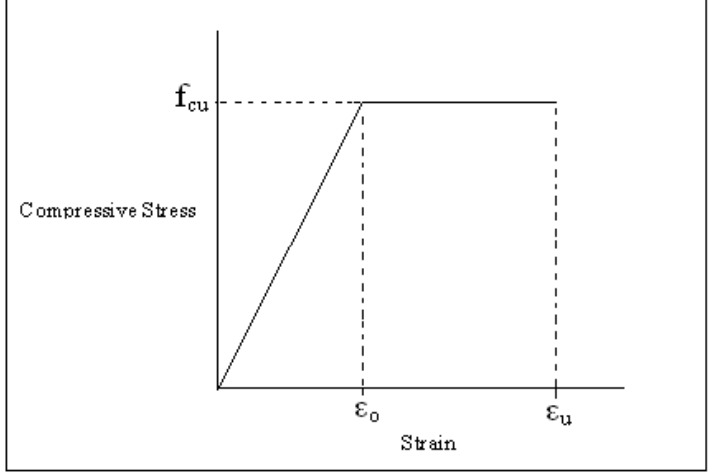

Figure 18: Idealized Compressive Stress-Strain Relationship of Ferrocement [ Ref. (10)]

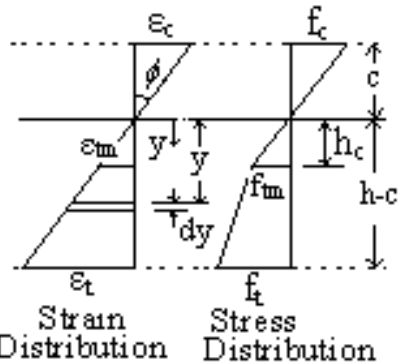

(b) Elastic-Plastic Stage( 1 )

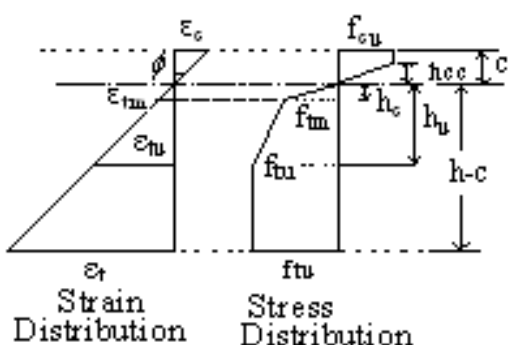

(d) Elastic-Plastic Stage ( 3 )

Figure (19) Stress and Strain Distribution Acting on Ferrocem ent Section 
The terminating point for this stage or the collapse occurs when the compressive strain in concrete reaches 0.0038 . The corresponding curvature becomes

$\phi_{e p 3}=\frac{0.0038}{c}$

\section{5-2 Load-Deflection Relationship}

Having the calculated moment-curvature relationship given in the previous section, loaddeflection relationship can be calculated for any type of beams loaded by various type of loads. For example, for a simply supported beam loaded by two central point load each P/2, the value of central deflection is given by

$\omega=\frac{P a}{48 E I}\left(4 a^{2}-3 l^{2}\right)$

The load - curvature relationship is given by :

$P=\frac{2 E I \phi}{a}$

Where EI is the value of flexural rigidity which varies with the cracking stages.

\section{5-3 Procedure for Analysis}

1- Specify an initial value of curvature.

2- Calculate the depth of compression zone.

3- Check the cracking limit.

4- Calculate the moment.

5- Calculate EI from the moment divided by curvature.

6- Calculate value of the load from Eq.( 25 )

7- Calculate the deflection from Eq. ( 24 ).

8- Repeat the steps 2 to 7 for another curvature increment and other cracking stages until the complete load- deflection response is obtained .

\section{5-4 Results of Analysis and Role of Span / Depth Ratio}

Test results from researches carried out on Ferro cement beams and slab strips [ 4,9,10 ] are used here to assess the accuracy of the proposed analytical procedure. From the comparison between test and predicted ultimate load, it is found that the analytical method is accurate for Ferro cement having wide ranges of compressive strength of mortar and wire mesh ratios but significantly sensitive to the span / depth ratio of the beam or slab strip. Figure (20) shows the test and calculated moment - curvature relationship for Ferro cement specimens of different span / depth ratios tested by Mansur ${ }^{[4]}$. From a comparison between test and calculated moment - curvature relationship it is observed that there is a good agreement between the two responses. Figure( 21 ) shows the load - deflection relationship calculated from the analytical procedure presented in this study and test results obtained by Walraven and Spierenburg ${ }^{[10]}$. It is observed from the figure that the analysis overestimates the load for all values of deflection. This occurs because the tested specimen has a span / depth ( L/h ) ratio 
equal to 35.7 and considered to be thin section. It is suggested ${ }^{[11]}$ that any slab strips having span / depth ratio larger than 22 considered to be very thin slabs and between 18 and 22 defined as thin slabs. In fact the analysis presented in this paper is not applied to very thin slabs and its predictions are accurate ( as shown from the comparison with test results ) only for the case of thick Ferro cement section $(\mathrm{L} / \mathrm{h}<18)$ and thin Ferro cement sections $(18<$ $\mathrm{L} / \mathrm{h}<22$ ) because very thin slabs suffer from large deflections and such effect should be incorporated in the analysis. Figure ( 22 ) shows the variation of the ratio of test to calculated ultimate load with the span / depth ratio. It is clearly shown that for Ferro cement specimens having $\mathrm{L} / \mathrm{h}$ ratio smaller than 22 the prediction is safe and accurate, regardless the wire mesh ratio and mortar strength. Walraven and Spierenburg ${ }^{[10]}$ in their analytical model on Ferro cement section assumed a constant value of the strain at which plastic stage commences, $\varepsilon_{\mathrm{ut}}$, equal to $1.2 \times 10^{-3}$. The authors believe that the value of $\varepsilon_{\mathrm{ut}}$ given in the present study using Eq. ( 11 ) is better and accurate for use in flexural analysis . Because the proposed value of $\varepsilon_{\mathrm{ut}}$ depends on the vital parameters of Ferro cement, namely tensile strain of matrix, tensile strength of matrix and ultimate tensile stress of Ferro cement which found to depend on both the matrix strength and reinforcement index $\left(\mathrm{V}_{\mathrm{R}} \mathrm{f}_{\mathrm{yR}}\right)$.

\section{6-CONCLUSIONS}

From the present study which contains test data and analytical procedures, the following conclusions can be drawn

1- Test results on Ferro cement disc specimens indicate that the tensile strength depends on both matrix strength and wire mesh ratio. An equation was proposed to calculate the tensile strength of Ferro cement depending on the matrix strength and reinforcement index ( $\left.\mathrm{V}_{\mathrm{R}} \mathrm{f}_{\mathrm{yR}}\right)$ [ Eq. ( 4 )].

2- Tensile strain at which plastic stage of stress-strain response commences was found to depend on tensile strain of matrix, tensile strength of matrix and ultimate tensile stress of Ferro cement [ Eq.( 11 ) ].

3- Flexural analysis was carried out to calculate the load - deflection relationship of Ferro cement beams and slab strips. The predictions of the analysis were compared with the test data from literature, and was found that the analysis is accurate and safe for calculating the load-deflection relationship, provided that the span/depth ratio not more than 22 .

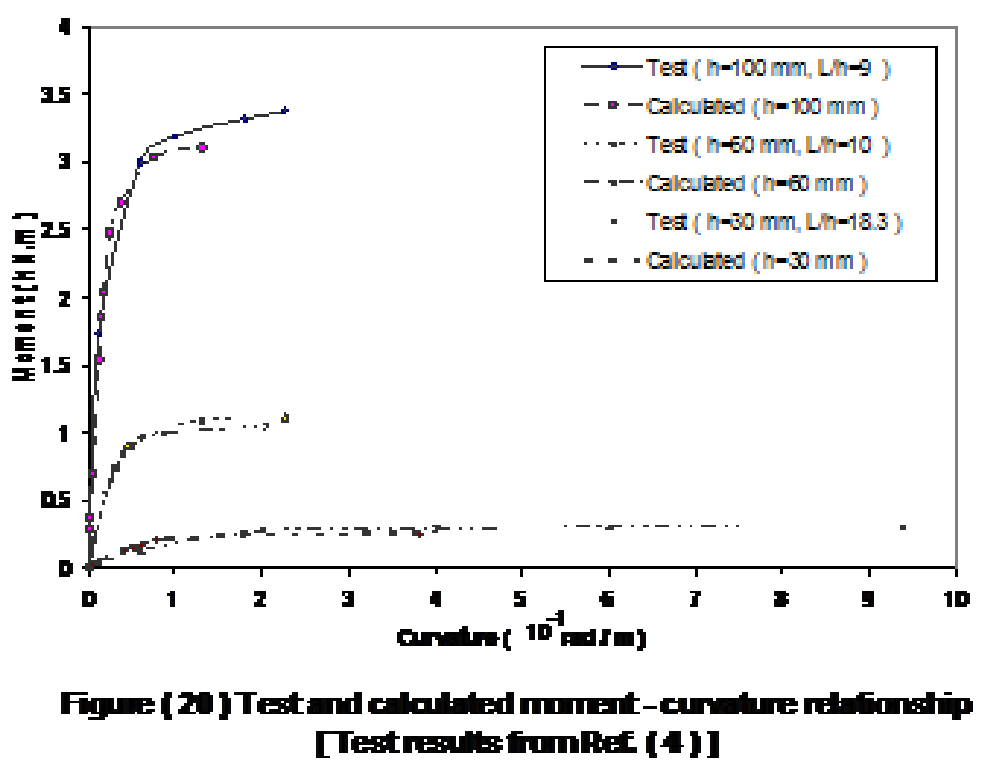




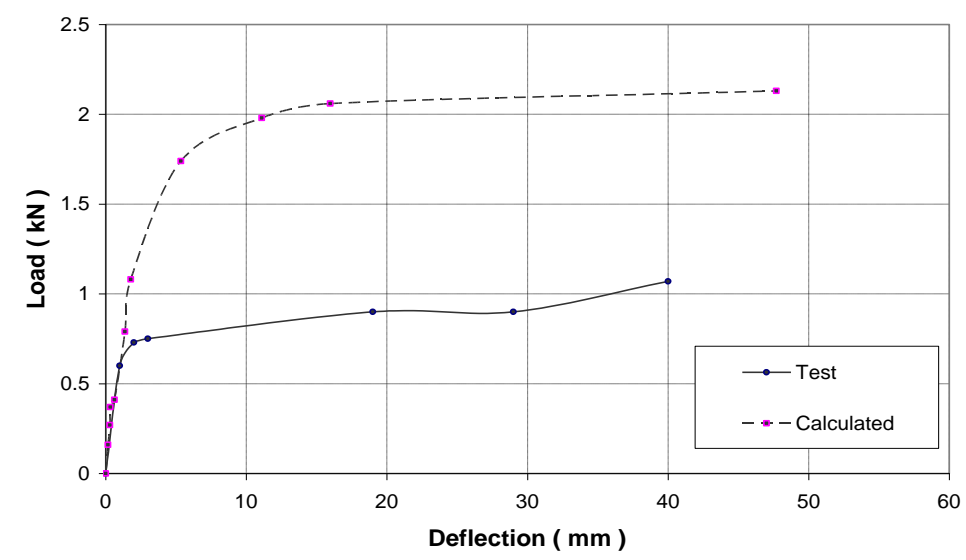

Figure ( 21 ) Test and Calculated Load - Deflection Relationship of Ferrocement [ Test results from Ref.( 10 )]

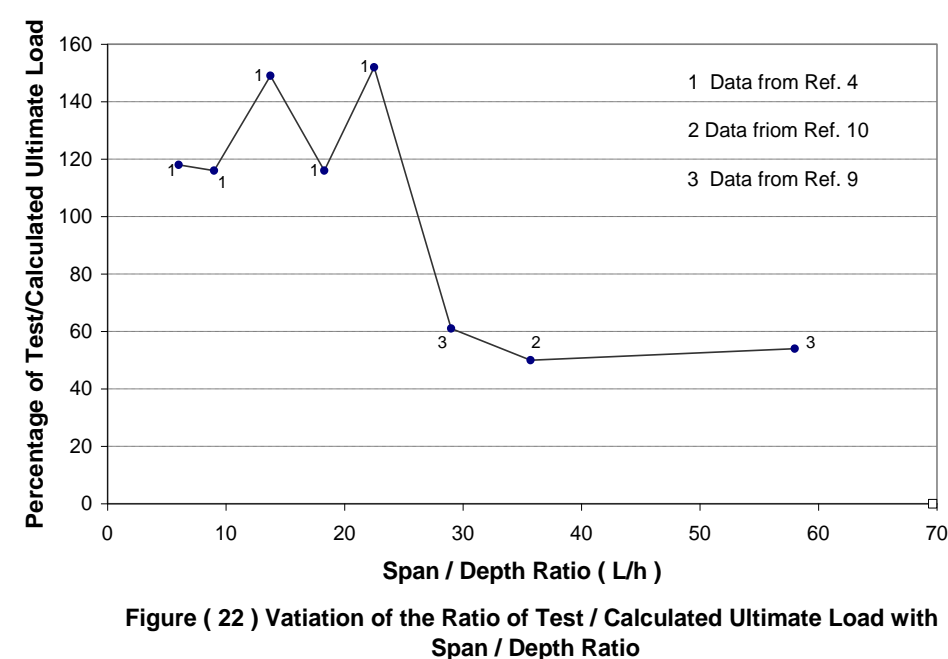

\section{Reference}

1- ACI Committee 549 , (2001) "State -of -the-Art Report on Ferro cement ", in Manual of Concrete Practice , Part ( 5 ), Detroit , Michigan

2- Baluguru, Perumalsamy N. , Naaman , Antoine E. , and Shah , S.P. ,( 1977 ) ," Analysis and Behavior of Ferro cement in Flexure, " Proceeding, ASCE , V. 103 , No. ST10, pp.1937-1951

3- Johnston , Colin D. , and Mattar, Samir G. , ( 1976 ), "Ferro cement in Tension and Compression ," Proceedings , ASCE , V.102, ST5 , pp.857-899

4- Mansur , M.A., ( 1988 ), “ Ultimate Strength Design of Ferro cement in Flexure , “ Journal of Ferro cement, Vol.18, No. 4 , pp. 385-395

5- Naaman , Antoine E., and Shah, Surendra P.,( 1971 )," Tensile Tests on Ferro cement ,"ACI Journal, Proceedings , V.68, No.5 , pp. 693-698

6- Oluokun , F.A.( 1991 ) , “ Prediction of Concrete Tensile Strength from Compressive Strength : Evaluation of Existing Relations for normal weight concrete " ACI Materials Journal , Vol. 88 , No. 3 , pp. 302-309 
7- Pama , R.P., Sutharatnachaiyarom , C. and Lee, S. L. ,( 1974 ), " Rigidities and Strength of Ferro cement ," Proceedings , First Australian Conf. on Engineering Materials , Univ. of New South Wales, Sydney, pp. 287-308

8- Shah, Surendra P. , and Baluguru , P.N. , ( 1984 ), “Ferro cement ," New Reinforced Concrete, R. N. Swamy , Ed. , Surrey Univ. Press , UK, pp. 1-51

9- Shareef, Yaman Sami , ( 2008 ), “ Flexural Behavior of Axially Restrained Ferrocement One-Way Slabs, " MSc Thesis, University of Duhok, 110 pp.

10- Walraven , J.C. and Spierenburg , S.E. J. ,( 1985 ) ," Behavior of Ferrocement with Chicken Wire Mesh Reinforcement “,Journal of Ferro cement, Vol. 15 , No. 1, pp.3-13

11- Welch , Ronald Wayne, ( 1999 ) ," Compressive Membrane and Capacity Estimates in Laterally Edge Restrained Concrete One-Way Slabs ," PhD. Thesis , University of Illinois at Urbana-Champaign .

\section{Notation}

a shear span

$\mathrm{A}_{\text {sf }}$ area of wire mesh reinforcement

$\alpha, \beta$ constants

b width of Ferro cement section

c depth of compression zone

n modular ratio $\left(E_{R} / E_{c}\right)$

$E_{R}$ elastic modulus of reinforcement

$E_{c}$ elastic modulus of Ferro cement material

$\mathrm{E}_{\mathrm{m}}$ elastic modulus of plain matrix

$\varepsilon_{\mathrm{c}} \quad$ compressive strain

$\varepsilon_{\mathrm{t}} \quad$ tensile strain

$\varepsilon_{\mathrm{tm}}$ cracking strain of matrix

$\varepsilon_{\mathrm{tu}}$ tensile strain corresponding to ultimate tensile stress

$\mathrm{f}_{\mathrm{c}} \quad$ compressive stress

$\mathrm{f}_{\mathrm{t}}$ tensile stress

$\mathrm{f}_{\text {tu }}$ tensile strength of Ferro cement

$\mathrm{f}_{\mathrm{tm}}$ tensile strength of the matrix

$\mathrm{f}_{\mathrm{ts}} \quad$ tensile stress carried by wire meshes

$\mathrm{f}_{\mathrm{c}}$ cylinder compressive strength of concrete

$f_{y R}$ yield stress of wire reinforcement

$\mathrm{h}$ depth of the Ferro cement section

$\psi \quad$ slope of the elastic-plastic portion of the tensile stress-strain relationship

$V_{R}$ ratio of the wire mesh reinforcement in the section

$M$ moment in general

$\Phi$ curvature in general 